\title{
On the issue of synonymic definitions acceptability in English monolingual lexicography
}

\author{
Boris Soldatov $^{1 *}$, Natalya Soldatova ${ }^{2}$ \\ ${ }^{1}$ Don State Technical University, World Languages and Cultures Department, 344000 \\ Rostov-on-Don, Russian Federation \\ ${ }^{2}$ Russian Customs Academy Rostov Branch, Foreign Languages Department, 344002 \\ Rostov-on-Don, Russian Federation
}

\begin{abstract}
The purpose of the present article was to examine the advantages and disadvantages of using synonymous words to define the meaning of a headword in English monolingual lexicography. The topicality of the study lies in the fact that, despite different opinions on the feasibility of this definition method, the latter has been widely used in English dictionaries for several centuries and is currently used. The authors proceeded from the Russian linguists' point of view, treating synonyms not as equivalent words, but as lexical units belonging to the same thematic group and so similar in meaning that their correct use in speech is impossible without accurate knowledge of their distinctive(semantic, stylistic, contextual) features. Synonymic definition has been considered as a kind of the language metalinguistic function implementation. The authors of the article highlight one of the ways to implement the metalinguistic function - synonymous intra-linguistic translation.
\end{abstract}

\section{Introduction}

The present article deals with the advantages and disadvantages of using synonymous words to define the meaning of the headword in English monolingual lexicography. Contrary to different opinions on the appropriateness of the present definition method, the latter has been widely used in English dictionaries for several centuries and is currently being used. The increase in the number of learners' dictionaries justifies increased attention to this method of defintion, because its misuse may confuse students and dictionary users.

In modern science, two points of view on synonyms as a phenomenon of lexical equivalence can be distinguished: identity and difference. The first point of view is generally accepted in British philological tradition (for example, the definition of synonyms given by D. Crystal [1, p. 196]). The majority of Russian linguists support a completely different point of view. In the Russian philological tradition not identity, but some similarity in expressing meanings shades is considered as the basis of synonymy, and the

\footnotetext{
* Corresponding author: spu-10.2.4@,donstu.ru
} 
primary attention is being paid to the differentiating function of synonyms. The comparison of synonymous words emphasizes not only the common in their meanings, but also the shades of meanings distinguishing the words being studied from each other.

Russian linguistic literature contains a completely different approach to the problem of lexical synonymy. For example, in the course of modern English lexicology Professor A. I. Smirnitsky refuses to consider this phenomenon, since lexicographical practice shows that there are no words in the language being absolutely identical in terms of content [2, c. 104]. One can agree with professor A. I. Smirnitsky in case of considering synonymy as semantic identity of two different language units. On the other hand, words can be close in meaning, and this is the cause of difficulties experienced by teachers, students, lexicographers, because it is necessary to display the differences between words, to explain and to illustrate them.

\section{Methods/Methodology}

The synonymic method consists in the selection of one or more synonyms to the lexical unit being defined and usually functions to disclose the words' lexical meanings by clarifying each of the word's scope of use. In this sense, such a method of definition can only be considered conditionally precise. Synonymic way of describing the meaning of the word is both philological and lexical in nature [4, p. 100].

Synonymous words in the dictionary definition perform the so-called metalinguistic function, characteristic not only of the dictionary. Modern logic distinguishes between an "objective language" speaking of an object and a "metalanguage" speaking of a language. Metalanguage is used not only in linguistics, but also in our everyday life. According to R. Jacobson, we use metalanguage without realizing the metalinguistic nature of our actions [5, p. 231]. When the speaker and the recipient of information somehow "verify" their semiological systems, the speech is aimed at verifying the content of statements and performs metalinguistic function. When analyzing the following statements:

To be flunked is to fail at the exam.

The sophomore is a second-year student.

R. Jacobson explains their metalinguistic nature, noting that they are aimed at establishing equivalence between the units and bear information only about the lexical code of the language [5, p. 233].

Metalinguistic function is an integral part of any speech communication. Knowledge of the language implies the ability to speak about the language. This metalinguistic operation allows revision and re-definition of the vocabulary used. R. Jacobson notes that the metalanguage, as well as the object language, is part of our verbal behavior and, thus, is a problem of linguistics [5, p. 234].

The basis of metalanguage is the natural human language, which has certain national characteristics. Consequently, metalanguage is nationally determined and is associated with the individual specificity of a particular language. In the field of semantics, it can be concluded that the semantic interaction between the units of natural language can be adequately described on the basis of metalanguage having the same nature as the object language.

The most complete and diverse expression of metalinguistic function of speech is found in the works of fiction, where there are a number of cases in which the synonymic paraphrase acts as such. The need to explain this or that lexical unit by means of synonymic words or phrases can be caused by the use of dialecticism, jargon, a special term, archaism - i.e. words, the understanding of which can cause difficulties for both the characters of the work of art, and the reader or listener. In such a situation, there is a so-called intralinguistic translation, i.e. a word or phrase that requires explanation or clarification for 
various reasons, is being described with the help of a synonymous word. If we turn to the definition of the word "translation" in the "Dictionary of linguistic terms" by O. S. Akhmanova, we can conclude that this phenomenon corresponds to the third meaning of this term [6, p. 309].

"Intra-linguistic translation" should be advised as the term to combine the phenomena of speech, which with all their diversity are united around a common, core concept of lexical equivalence, i.e. some original content and different ways of expressing it. Those who use the language constantly strive to equalize the content even if the expression is different.

Synonyms in fiction are also used for "speech characteristics" of the novel characters. Therefore, when studying specific examples from fiction, it is not enough to simply state the fact that one character uses one word, and the second one uses another word. The reason for the use of these words can't be determined by the narrow context, it needs to put the whole scene in a wide context of the whole work, which enables to give a fairly complete picture of the characters as "linguistic personalities" [7, p. 47].

It seems appropriate to conduct a comparative analysis of intra-linguistic translation in fiction and in the dictionary. Let's study a few examples.

1.'I mean that the reason why the game yesterday struck you as slow was that the wicket — I should say the turf - was sticky - that is to say, wet. Sticky is a technical term, sir.'[8, p. 17].

It is an excerpt from the conversation between two characters of the novel. One of them, Mr. Crocker, who came to England from America five years ago and was interested in baseball all his life, has just started to be interested in the English national game - cricket and does not know all its features. The second character is his servant Baileys, a cricket player in the past, who explains Mr. Crocker the meaning of the word "sticky" - more precisely, the meaning in which the word is used by cricket players.

It should be noted that in this case the phrase "that is to say" ("so to speak") is used to describe the meaning, i.e. the meanings of the words "sticky" and "wet" are only partially equalized. Moreover, at the end of the explanation, the character mentions that the word "sticky" is a technical term. This is an example of "inter-register" intra-linguistic translation: a word belonging to a special vocabulary is explained by means of a neutral word. The author also used this technique to explain what is meant by the word "sticky" to the reader having no idea about cricket.

2."He feared the wrath of that millionaire philatelist". "Millionaire what?" - asked a Small Bass.

"Sir Leopold," explained Mr.Mulliner, "collected stamps".

The Small Bass said that he had always thought that a philatelist was a man who was kind to animals.

"No", said Mr. Mulliner, "a stamp collector" [9, p. 129].

An excerpt from the conversation between the main character of the novel Mr. Mulliner and one of his friends shows that Small Bass - as can be seen from his remarks - is a man who is narrow-minded and largely uninformed. He certainly can't know such a rare word as "philatelist", especially since it is not a native English word, but of Greek origin. The rare word "philatelist", known only to those people who collect stamps, is explained by the more common word "stamp collector".

Thus, the difference between the words "philatelist" and "stamp collector" is shown by the author through the context. Laughing at his character's ignorance, P. G. Woodhouse alludes to the fact that the word "philatelist" belongs to the vocabulary known only to a more educated person. This example can also be considered as a case of "inter-register" intra-linguistic translation. 
Consider the interpretation of words in the short explanatory dictionary Pocket Oxford Dictionary of Current English [10].

1. The word "sticky" is interpreted as follows: "tending to stick or adhere to things" [10, p. 532]. Due to its small size, this dictionary does not cover all the meanings of the word "sticky". So we had to turn to a more detailed dictionary, The Concise Oxford Dictionary of Current English [11]. The latter contains the following interpretation of the expression "sticky wicket": "sticky wicket (in cricket) — pitch drying after rain and difficult for batsmen" [11, p. 1044]. This definition could be considered as a case of the intra-linguistic translation which is more accurate than the one in the literary text (though not with the help of a word, but with the help of a phrase), since the label "in cricket" is used to explain the meaning of the phrase.

2. The word "philatelist" is presented in Pocket Oxford Dictionary [10, p. 490] as a derivative of the word "philately", which is interpreted as "stamp collecting". If we remember that in the literature the word "philatelist" is explained as "stamp collector", we can conclude that the two definitions given by us are not fundamentally different from each other. But if the author of the book makes an attempt to show the difference between the words in the context of a certain scene, they are equalized within the framework of the dictionary entry. The Concise Oxford Dictionary States that the word "philatelist" as borrowed, of Greek origin [11, p. 952].

Basing on the definition of language as a distinctive sign system [6, p. 541] (see "Dictionary of linguistic terms" by O. S. Akhmanova), we arrive at the conclusion that the use of synonymic intra-linguistic translation to define the meaning of the headword can be considered as a kind of semiotic phraseology.

Since language is recognized as a sign system, although with reservations that it is a sign system of a special kind, linguistics is becoming part of semiotics. Therefore, the section can be pointed out in philological science, - philological (linguistic) semiotics studying the problems of interaction between sign theory (semiotics) and semasiology, dealing with lexical meanings of words.

It seems reasonable to single out the main categories of linguistic semiotics. The first of these categories is the "disembodiment" of meaning with the unity of the two sides of the word - content and expression. The second linguistic-semiotic category - "arbitrariness" implies that the sign, including the linguistic one, is arbitrary, being the unity of the given content and the given expression "by establishing". The third category of linguosemiotics "uniqueness" - implies the obligation of the natural unity of content and expression for the word to be recognized as a sign [12, p. 96].

Let us consider the linguistic and semiotic aspects in monolingual lexicography. It is known that the first step in the study of the lexical composition of the language is to explain the meaning of the word and the representation of its semantics in the dictionary. The meaning of the word is determined on the basis of the contexts of its use in various works of speech in order to show what the word means in the entirety of its semantics as part of this philological tradition.

It is necessary to distinguish between three types of phraseology in lexicography: "semiotic" phraseology, i.e. phrases used for the definition of the word meanings compiled by the author for this very metalinguistic purpose; "philological" phraseology, i.e. the uses of the word recorded in the philological thesaurus of the language; "illustrative" phraseology is presented by phrases created by the lexicographer to show the word in action and to prove the provisions given in the definition or interpretation of the word's menings.

Thus, the term "semiotic phraseology" refers to the section of phraseology dealing with the interpretation of words, i.e. explanation of the meaning (or meanings), which is embedded in this language lexical unit. A definition in an explanatory dictionary is an 
explanation of the meaning of a word performed by means of the same language. Considered as a variation of the phrase, it is a kind of intra-linguistic translation.

Semiotic phraseology is distinguished by the fact that it is created by the lexicographer for well-defined "interlinguistic" purposes. Definitions in dictionaries are semiotic in the sense that their "intention", their purpose and functioning are fundamentally different from the other two types of dictionary phraseology: philological and illustrative. "Interpretive" phraseology is thought of as a semiotic fact, as a kind of interlinguistic beginning, because it is intended to describe the meanings of interpreted lexical units [13, p. 54].

\section{Results}

Before considering the material, it is necessary to identify the main types of synonymic intra-linguistic translation and determine the trends in the use of a particular type in the analyzed dictionaries. Synonymic intra-linguistic translation in the experimental material is presented in two types:

1) simple intra-linguistic translation, i.e. complete equalization of a word with its synonymic definition, for example:

laundress, $\mathrm{n}$ - washerwoman [10, p. 235];

2) complicated intra-linguistic translation, when the right part of the entry is complicated by other lexicographic techniques.

As for the cases of complete equalization of the headword with its definition, it is reasonable to highlight such principles of the conjugation of synonymous words as:

1) etymological (interpretation of the borrowed word through native English: khan ruler [10, p. 203], and Vice versa: lessen - diminish [10, p. 240]; use of the borrowed word for the interpretation of another borrowed unit - limitary — restrictive [10, p. 253]; use of native English words for the interpretation of the meaning of another native English word - stitch - sew [10,p. 589]);

2) the principle of morphological complexity (the use of morphologically simple words for the interpretation of morphologically complex words - sleep-walker - somnambulist [10, p. 571]; the use of morphologically complex words for the interpretation of morphologically simple - khaki - dull - yellow [10, p. 204]; use for the interpretation of the word of the same degree of morphological complexity as of the word defined loquacious - talkative [10, p. 268]);

3) lexico-morphological (interpretation by means of a potential word - legality lawfulness [10, p. 264]);

4) species-generic (explaining the meaning of words by means of a hyperonym - ling a sea-fish [10, p. 266]; stitchwort - a plant [10, p. 539]).

The following kinds of complicated synonymous intra-linguistic translation have been identified as a result of the study:

1. Definition of meaning with description of combinability of the headword: kidnap steal (child) [14, p. 432]; lighten — (of eyes) flash [14, p. 441]; syllable — utter (name, word) [14, p. 967].

2. Definition with reference to stylistic and dialectal affiliation of the word:

kid — (sl)child [10, p. 196]; ken — (Sc) know [10, p. 198];

lather - (sl) thrash [10, p. 251]; lucid — (poet) bright [10, p. 276];

spadger - (sl) sparrow [10, p. 519].

3. Interpretation with information about the origin of the word:

libidinous - lustful [ L libido -lust] [14, p. 440];

supersession - superseding [L sedeo-sit] [14, p. 961].

4. In addition, within the framework of one dictionary entry, several ways of words definition complicating can be used: 
kern - (hist) peasant [Ir] [10, p. 201];

limn - (arch) paint (picture) [14, p. 445];

slippy — (vulg.) slippery (look slippy, sl make haste) [14, p. 951].

\section{Conclusion}

Thus, due to the absence of absolutely identical lexical units in the language, the definition by means of simple intra-linguistic translation, i.e. complete identification of synonyms in the dictionary entry can't be considered as absolutely accurate, because it does not correspond to all three principles of linguistic semiotics. The definition, in which the equalization of synonymous words within the dictionary entry is complicated by using different lexicographical techniques can be considered more correct from linguistic and semiotic points of view. Such interpretations can be considered as corresponding to all three linguistic-semiotic principles, and above all — to the principle of "uniqueness". In other words, when explaining the meaning of the word with the help of a synonymous lexical unit, on the one hand, the headword within the dictionary entry is equalized with a synonymous word used for its definition, and on the other hand, through a series of lexicographic techniques, it is indicated that the lexical units being studied are not absolutely identical.

\section{References}

1. D. Crystal, Language and the Internet (Cambridge University Press, New York, 2003)

2. A.I. Smirnitsky, Lexicology of the English language (MSU, Moscow, 1998)

3. V.A. Kozyrev, V.D. Chernyak, Vestnik Cherepovets state University. 1, 32-38 (2015)

4. V.A. Bukina, Bulletin of Leningrad state University. 99-102 (2014)

5. R. Jakobson, On Language (New York, 1990)

6. O.S. Akhmanova, Dictionary of linguistic terms (URSS, Moscow, 2009)

7. E.M. Rucinska, Russian speech: a popular scientific journal. 4, 46-49 (2013)

8. P.G. Wodehouse, Piccadilly Jim (Penguin Books, London, 2009)

9. P.G.Wodehouse, The World of Mr. Mulliner (Barie \& Jenkins, London, 2010)

10. Pocket Oxford Dictionary of Current English (Oxford at the Clarenden Press, Oxford, 2012)

11. The Concise Oxford Dictionary of Current English, seventh edition (Oxford Univ. Press, Bombay, 2010)

12. O. M. Karpova, English lexicography: Textbook for students of philological faculties of higher educational institutions (Academy, Moscow, 2016)

13. M.V. Moiseev, English Lexicography: teaching aid: for students of specialties 022900 "Translation and translation studies" and 022600 "Theory and methods of teaching foreign languages" (Omsk state University Publ., Omsk, 2009)

14. Oxford Advanced Learners' Dictionary of Current English (Oxford Univ. Press, Oxford, 2009) 